\title{
Occurrence of Mycobacterium avium subspecies paratuberculosis across host species and European countries with evidence for transmission between wildlife and domestic ruminants
} Karen Stevenson*1, Julio Alvarez ${ }^{2}$, Douwe Bakker ${ }^{3}$, Franck Biet ${ }^{4}$, Lucia de Juan $^{2,5}$, Susan Denham ${ }^{1}$, Zoi Dimareli' ${ }^{6}$, Karen Dohmann ${ }^{7}$, Gerald F Gerlach7 , Ian Heron ${ }^{1}$, Marketa Kopecna ${ }^{8}$, Linda May ${ }^{1}$, Ivo Pavlik8, J Michael Sharp ${ }^{9}$, Virginie C Thibault ${ }^{4,11}$, Peter Willemsen ${ }^{3}$, Ruth N Zadoks ${ }^{1}$ and Alastair Greig10

Address: ${ }^{1}$ Moredun Research Institute, Pentlands Science Park, Bush Loan, Penicuik EH26 0PZ, UK, ${ }^{2}$ Centro de Vigilancia Sanitaria Veterinaria (VISAVET), Universidad Complutense, Avenida Puerta de Hierro s/n, 28040 Madrid, Spain, ${ }^{3}$ Central Institute of Wageningen University, Edelhertweg 15, $8200 \mathrm{AB}$ Lelystad, The Netherlands, ${ }^{4}$ UR1282, Infectiologie Animale, Santé Publique (IASP-311), INRA centre de Tours, F-37380 Nouzilly, France, ${ }^{5}$ Departamento de Sanidad Animal, Facultad de Veterinaria, Universidad Complutense, Avenida Puerta de Hierro s/n, 28040 Madrid, Spain, ' Veterinary Institute of Thessaloniki, NAGREF, Thermi 57001, P.B.O: 60272 Thessaloniki, Greece, ${ }^{7}$ Institut für Mikrobiologie Stiftung Tierärztliche Hochschule Hannover, Bischofsholer Damm 15, 30173 Hannover, Germany, ${ }^{8}$ Veterinary Research Institute, Hudcova 70, 62100 Brno, Czech Republic, ${ }^{9}$ Veterinary Laboratories Agency, Pentlands Science Park, Bush Loan, Penicuik EH26 0PZ, UK, ${ }^{10}$ Scottish Agricultural College, Veterinary Science Division, Cleeve Gardens, Oakbank Road, Perth, UK and ${ }^{11}$ Laboratoire Microorganismes, Génomes et Environnement, UMR CNRS 6023, Université Blaise Pascal, 63177 Aubière cedex, France

Email: Karen Stevenson* - karen.stevenson@moredun.ac.uk; Julio Alvarez - jalvarez@visavet.ucm.es; Douwe Bakker - douwe.bakker@wur.nl; Franck Biet - Franck.Biet@tours.inra.fr; Lucia de Juan - dejuan@visavet.ucm.es; Susan Denham - susan.denham@moredun.ac.uk; Zoi Dimareli - dimareliz@hotmail.com; Karen Dohmann - dohmann@ivd-gmbh.de; Gerald F Gerlach - gfgerlach@gmx.de; Ian Heron - ian.heron@moredun.ac.uk; Marketa Kopecna - mkopecna@vri.cz; Linda May - linda.may@moredun.ac.uk; Ivo Pavlik - pavlik@vri.cz; J Michael Sharp -m.j.sharp@vla.defra.gsi.gov.uk; Virginie C Thibault - Virginie.Thibault@univ-bpclermont.fr; Peter Willemsen - peter.willemsen@wur.nl; Ruth N Zadoks - ruth.zadoks@moredun.ac.uk; Alastair Greig - m.greig630@btinternet.com * Corresponding author

Published: 7 October 2009

BMC Microbiology 2009, 9:2/2 doi:10.1/86/147|-2/80-9-2/2
Received: 20 April 2009

Accepted: 7 October 2009

This article is available from: http://www.biomedcentral.com//47I-2/80/9/2/2

(C) 2009 Stevenson et al; licensee BioMed Central Ltd.

This is an Open Access article distributed under the terms of the Creative Commons Attribution License (http://creativecommons.org/licenses/by/2.0), which permits unrestricted use, distribution, and reproduction in any medium, provided the original work is properly cited.

\begin{abstract}
Background: Mycobacterium avium subspecies paratuberculosis (Map) causes an infectious chronic enteritis (paratuberculosis or Johne's disease) principally of ruminants. The epidemiology of Map is poorly understood, particularly with respect to the role of wildlife reservoirs and the controversial issue of zoonotic potential (Crohn's disease). Genotypic discrimination of Map isolates is pivotal to descriptive epidemiology and resolving these issues. This study was undertaken to determine the genetic diversity of Map, enhance our understanding of the host range and distribution and assess the potential for interspecies transmission.

Results: I64 Map isolates from seven European countries representing 19 different host species were genotyped by standardized IS900 - restriction fragment length polymorphism (IS900-RFLP), pulsed-field gel electrophoresis (PFGE), amplified fragment length polymorphisms (AFLP) and mycobacterial interspersed repeat unit-variable number tandem repeat (MIRU-VNTR) analyses. Six Pstl and I 7 BstEII IS900-RFLP, 3I multiplex [SnaBI-Spel] PFGE profiles and 23 MIRU-VNTR profiles were detected. AFLP gave insufficient discrimination of isolates for meaningful genetic analysis.
\end{abstract}


Point estimates for Simpson's index of diversity calculated for the individual typing techniques were in the range of 0.636 to 0.664 but a combination of all three methods increased the discriminating power to 0.879 , sufficient for investigating transmission dynamics. Two predominant strain types were detected across Europe with all three typing techniques. Evidence for interspecies transmission between wildlife and domestic ruminants on the same property was demonstrated in four cases, between wildlife species on the same property in two cases and between different species of domestic livestock on one property.

Conclusion: The results of this study showed that it is necessary to use multiple genotyping techniques targeting different sources of genetic variation to obtain the level of discrimination necessary to investigate transmission dynamics and trace the source of Map infections. Furthermore, the combination of genotyping techniques may depend on the geographical location of the population to be tested. Identical genotypes were obtained from Map isolated from different host species co-habiting on the same property strongly suggesting that interspecies transmission occurs. Interspecies transmission of Map between wildlife species and domestic livestock on the same property provides further evidence to support a role for wildlife reservoirs of infection.

\section{Background}

Mycobacterium avium subspecies paratuberculosis (Map) causes paratuberculosis or Johne's disease, a fatal chronic granulomatous enteritis. The disease occurs worldwide and is responsible for significant economic losses to livestock and associated industries [1,2]. It is endemic in Europe with only Sweden maintaining paratuberculosisfree status. The epidemiology is poorly understood and there are important questions still to resolve, particularly with respect to interspecies transmission. Map infects principally ruminants but over the past decade it has become apparent that the organism has a much broader host range including monogastric species [3-5]. The infection of humans with Map and possible association with Crohn's disease remains a controversial issue and requires more study [6,7]. The strain types involved and the extent to which interspecies transmission occurs have still to be elucidated. Evidence also is accumulating regarding the existence of potential wildlife reservoirs, for example, infected rabbits appear to be a particular problem in some areas of Scotland [3] but the role of such wildlife reservoirs in the epidemiology of the disease has still to be clarified.

Our knowledge and understanding of the epidemiology of Map has been hindered for many years by our inability to discriminate Map from the environmental species of Mycobacterium avium ( $M$. avium) and to differentiate between Map isolates from different host species and different geographic locations. Recent advances in molecular biology have led to the refinement and development of molecular typing methods with sufficient discriminatory power to differentiate between $M$. avium subspecies and different Map isolates [8]. Genome analyses have revealed two major strain groups designated 'Type I', or 'sheep or S type' and 'Type II' or 'cattle or C type'. A sub-type of Type I strains designated 'Type III' or 'intermediate or I type' is found in sheep and goats. All three of these strain types can be differentiated by restriction fragment length polymorphism coupled with hybridization to IS900 (IS900RFLP) $[9,10]$ or pulsed-field gel electrophoresis (PFGE) analyses $[11,12]$ and by a PCR assay based on single nucleotide polymorphisms in the gyrA and gyrB genes [13]. Single nucleotide polymorphisms in the IS1311 element also distinguish three types designated 'S' (sheep), ' $\mathrm{C}$ ' (cattle) and 'B' (bison) $[14,15]$. In this case the assay cannot distinguish between Types I and III and the 'B' type is a sub-type of Type II strains. In silico genome comparisons and techniques such as representational difference analysis and microarray analysis have identified sequence polymorphisms unique to either Type I or II strains and these have been used to develop PCRs for discriminating these strain groups [16-21]. The purpose of this study was to investigate the molecular diversity of Map isolates from a variety of hosts across Europe to enhance our understanding of the host range and distribution of the organisms and assess the potential for interspecies transmission. Previous studies have revealed limited genetic diversity; therefore, to maximise strain differentiation we evaluated several different molecular typing techniques in isolation and in combination; IS900-RFLP, PFGE and PCR-based techniques including amplified fragment length polymorphisms (AFLP) and mycobacterial interspersed repeat unit-variable number tandem repeat (MIRU-VNTR).

\section{Results}

AFLP typing was performed at the Central Institute of Wageningen University, Lelystad, The Netherlands and MIRU-VNTR at INRA, Nouzilly, France. For PFGE and IS900-RFLP typing, the field isolates were split between two labs. PFGE typing was undertaken at the Moredun Research Institute, Scotland, UK and VISAVET, Madrid, Spain. IS900-RFLP typing was carried out at the Veterinary 
Research Institute in Brno, Czech Republic and VISAVET. Published standardized typing procedures were used as described in Materials and Methods. The only difference in procedures between laboratories was that at VISAVET the IS900-RFLP analysis was performed using the agarose plugs prepared for PFGE to avoid having to perform two separate DNA preparations for the different typing techniques. The correct profiles were reported by all laboratories for the duplicate isolates included to check reproducibility. All typing techniques correctly reported that the Mycobacterium phlei (M. phlei), Mycobacterium bovis BCG (M. bovis BCG) and IS901 positive M. avium were not Map. One field isolate, EU112 was found to be IS901 positive $M$. avium (it is not known if the isolate is M. avium subsp. avium or M. avium subsp. silvaticum) and not Map as was originally suspected. Another isolate, EU169 was found to be a mixed culture. Isolates one to 50 were typed at Institut für Mikrobiologie Stiftung Tierärztliche Hochschule Hannover, Hannover, Germany using the Type I/ Type II PCR as described by Dohmann et al. [17]. EU25 and EU30 were identified as Type I and all other field isolates as Type II. These results correlated with the strain type as determined by PFGE. This PCR [17] cannot discriminate between Type I and Type III and as strain types could be discerned from the PFGE profiles, it was not considered necessary to determine the strain type of the remaining isolates by PCR. It was not possible to type all of the isolates with all typing methods as some laboratories had difficulties in subculturing some isolates to prepare sufficient cells for analyses. A total of 123 Map isolates were typed by IS900-RFLP, PFGE and MIRUVNTR.

\section{IS900-RFLP typing}

IS900-RFLP typing data were obtained for 147 Map isolates (Table 1 and see supplementary dataset in Additional file 1). It was not possible to obtain PstI profiles for 55 isolates or clear BstEII profiles for five isolates. There was a problem using agarose plug DNA for IS900-RFLP typing with PstI as the enzyme would not cleave in the presence of agarose. Extraction of the DNA from the agarose and repeat PstI digestion was not attempted. As expected, profiles were not obtained for the negative control strains $M$. bovis BCG, M. phlei and IS901 positive $M$. avium. A total of six PstI profiles were found among 93 isolates: $\mathrm{B}(\mathrm{n}=88) ; \mathrm{G}(\mathrm{n}=1) ; \mathrm{I}(\mathrm{n}=1) ; \mathrm{K}(\mathrm{n}=1) ; \mathrm{R}(\mathrm{n}=1)$; and $U(n=1)$. Seventeen BstEII profiles were detected among 142 isolates: C1 $(\mathrm{n}=71) ; \mathrm{C} 17(\mathrm{n}=49)$; C5 ( $\mathrm{n}=$ 5); C9 $(\mathrm{n}=3) ; \mathrm{C} 16(\mathrm{n}=2)$ and single isolates with $\mathrm{C} 10$, C18, C22, C27, C29, C35, C36, C38, C39, S4, I4 and I5. Ten different combined PstI-BstEII profiles were recorded among the 88 isolates that were characterised with both enzymes: B-C1 $(\mathrm{n}=42)$; B-C17 $(\mathrm{n}=36)$; B-C9 $(\mathrm{n}=3)$ and single isolates of B-C5, B-C16, G-C35, I-C29, K-C17, R-I4 and U-C16. The B-C17 profile was predominant in Scot- land in this cohort of isolates, specifically in the regions of Aberdeenshire, Angus, Borders and Perth and Kinross (Table 1 and see supplementary dataset in Additional file 1 and Additional file 2: Table S1). The C1 profile was more widely spread across Europe and was found in the Czech Republic, Greece, Finland, The Netherlands, Norway and Spain, (Table 1 and see supplementary dataset in Additional file 1 and Additional file 2: Table S1).

\section{PFGE typing}

PFGE typing data were obtained for 145 Map isolates (Table 1 and Figure 1). Twenty four different SnaBI profiles were detected in this panel of isolates: $2(\mathrm{n}=91) ; 1$ $(\mathrm{n}=15) ; 15(\mathrm{n}=9) ; 29(\mathrm{n}=4) ; 34(\mathrm{n}=4) ; 3(\mathrm{n}=3) ; 38$ $(\mathrm{n}=2)$ and 5, 9, 16, 18, 20, 26, 27, 30, 31, 32, 33, 36, 37, 39, 40, 41, 58 ( $\mathrm{n}=1 \mathrm{each})$; and 23 distinct SpeI profiles: 1 ( $\mathrm{n}=102) ; 25(\mathrm{n}=8) ; 2,15,22$ ( $\mathrm{n}=4$ each $) ; 17,19,21$, 30,32 ( $\mathrm{n}=2$ each) and $7,10,11,16,18,20,23,24,27$, $28,29,31,64$ ( $n=1$ each). The combination of both enzyme profiles gave 31 different multiplex profiles: [2-1] $(\mathrm{n}=83)$; [1-1] $(\mathrm{n}=15) ;[15-25](\mathrm{n}=8)$; [29-15],[34-22] ( $\mathrm{n}=4$ each); [3-2] ( $\mathrm{n}=3)$; [2-19],[2-30],[38-32] $(\mathrm{n}=2$ each) and [2-10], [2-17], [2-21], [2-31], [5-2], [9-7], [1516], [16-11], [18-1], [20-1], [26-1], [27-18], [30-21], [3117], [32-29], [33-20], [36-27], [37-23], [39-24], [40-28], [41-1],[58-64] ( $\mathrm{n}=1$ each). By far the most widely distributed PFGE type was [2-1], which was found in the Czech Republic, Finland, The Netherlands, Norway, Scotland and Spain (Table 1 and see supplementary dataset in Additional file 1 and Additional file 2: Table S1). PFGE type [1-1] was the next most common occurring in the Czech Republic, Finland, The Netherlands and Spain (Table 1 and see supplementary dataset in Additional file 1 and Additional file 2: Table S1). Profile [2-30] was found in The Netherlands and Scotland and the other profiles were found in only one country (Table 1 and see supplementary dataset in Additional file 1 and Additional file 2: Table S1). The numbers of isolates detected with these profiles are too small to determine if these multiplex profiles truly are restricted in their geographical location.

\section{AFLP typing}

A representative subset of 68 Map isolates in the typing panel were analysed by AFLP. The DNA restriction patterns generated by EcoRI and MseI showed patterns that met the conditions for analyses such as fragment sizes, number of bands and ratio of fully versus partially digested fragments. The Map isolates, as a group, clearly clustered differently from other mycobacterial species such as Mycobacterium marinum, Mycobacterium tuberculosis and M. phlei. However, within the group of Map isolates a low degree of genetic diversity was detected, with isolates displaying between 90 and 95\% homology. The reproducibility of the technique was assessed and it was concluded that on average the calculated similarities using the Pear- 
Table I: Combined PFGE, MIRU-VNTR and IS900-RFLP profiles by Map origin

\begin{tabular}{|c|c|c|c|c|c|c|c|c|c|c|}
\hline \multirow{2}{*}{$\begin{array}{l}\text { Profile } \\
\text { PFGE }^{3}\end{array}$} & \multirow[b]{2}{*}{$\begin{array}{l}\text { MIRU- } \\
\text { VNTR }{ }^{4}\end{array}$} & \multirow[b]{2}{*}{$\begin{array}{l}\text { IS900- } \\
\text { RFLP } 5\end{array}$} & \multirow[t]{2}{*}{ No of isolates } & \multicolumn{7}{|c|}{ Country'-Host $^{2}$} \\
\hline & & & & $\mathbf{C Z}$ & ES & $\mathbf{F L}$ & GR & NL & No & sco \\
\hline$[1-1]$ & I & $\mathrm{Cl}$ & 2 & RD & & & & G & & \\
\hline$[1-1]$ & 2 & $\mathrm{Cl}$ & 7 & $C, R D$ & $\mathrm{C}$ & $C(2)$ & & $\mathrm{C}, \mathrm{RD}$ & & \\
\hline$[1-1]$ & 2 & $\mathrm{C} 18$ & 1 & & & $\mathrm{C}$ & & & & \\
\hline$[1-1]$ & 2 & $\mathrm{C5}$ & 1 & & & & & $C$ & & \\
\hline$[1-1]$ & 6 & $\mathrm{Cl}$ & 2 & & & & & $C(2)$ & & \\
\hline$[2-1]$ & I & $\mathrm{Cl}$ & 13 & $C(4), F D, M$ & $\mathrm{C}$ & $C(2)$ & & & $\mathrm{G}(3), \mathrm{S}$ & \\
\hline$[2-1]$ & 1 & $\mathrm{C} 9$ & 1 & $\mathrm{H}$ & & & & & & \\
\hline$[2-1]$ & 1 & $\mathrm{Cl}$ & 39 & & & & & & $\mathrm{C}, \mathrm{S}$ & $\begin{array}{l}\text { B, C(6), CR, F(2), H, } \\
\text { R(I3), RK, S(7), ST(3), } \\
\text { W, WM }\end{array}$ \\
\hline$[2-1]$ & 2 & $\mathrm{Cl}$ & 2 & & & & & & & $C(2)$ \\
\hline$[2-1]$ & 2 & $\mathrm{Cl}$ & 9 & C & FD & & & $C(2), G, S(4)$ & & \\
\hline$[2-1]$ & 2 & $\mathrm{C5}$ & I & & & & & C & & \\
\hline$[2-1]$ & 2 & $\mathrm{C} 36$ & I & & & & & C & & \\
\hline$[2-1]$ & 5 & $\mathrm{ClO}$ & I & $\mathrm{C}$ & & & & & & \\
\hline$[2-1]$ & 19 & $\mathrm{Cl}$ & 1 & & & & & & & $S$ \\
\hline$[2-1]$ & 24 & $\mathrm{Cl}$ & i & & & & & $S$ & & \\
\hline$[2-1]$ & 22 & $\mathrm{C} 38$ & 1 & & & & & G & & \\
\hline$[2-1]$ & 25 & $\mathrm{Cl}$ & 1 & & & & & & & $\mathrm{R}$ \\
\hline$[2-10]$ & 1 & $\mathrm{Cl}$ & 1 & & & & & & G & \\
\hline$[2-17]$ & 2 & $\mathrm{C} 22$ & 1 & & & & & $S$ & & \\
\hline$[2-19]$ & 2 & $\mathrm{C} 5$ & 2 & & & & $\mathrm{G}, \mathrm{S}$ & & & \\
\hline [2-30] & 1 & $\mathrm{Cl} 6$ & 1 & & & & & $\mathrm{RD}$ & & \\
\hline$[2-30]$ & 25 & $\mathrm{Cl} 6$ & 1 & & & & & & & $w$ \\
\hline [3-2] & 1 & $\mathrm{Cl}$ & 3 & & & & & & & $\mathrm{~F}, \mathrm{G}, \mathrm{J}$ \\
\hline [5-2] & I & $\mathrm{Cl} 7$ & 1 & & & & & & & $S$ \\
\hline [9-7] & 21 & S4 & 1 & & & & & & & $S$ \\
\hline$[15-16]$ & 38 & $\mathrm{Cl}$ & 1 & & G & & & & & \\
\hline$[15-25]$ & 26 & $\mathrm{Cl}$ & 7 & & $\mathrm{G}(7)$ & & & & & \\
\hline$[16-11]$ & 20 & 15 & 1 & & $\mathrm{G}$ & & & & & \\
\hline$[18-1]$ & 13 & $\mathrm{Cl}$ & 1 & & G & & & & & \\
\hline$[20-1]$ & 1 & $\mathrm{Cl}$ & 1 & C & & & & & & \\
\hline$[26-1]$ & 35 & $\mathrm{Cl}$ & I & C & & & & & & \\
\hline [27-18] & 2 & $\mathrm{C} 27$ & 1 & & C & & & & & \\
\hline$[29-15]$ & 36 & $\mathrm{Cl}$ & 1 & & & & G & & & \\
\hline [29-15] & 37 & $\mathrm{Cl}$ & 3 & & & & $\mathrm{G}(3)$ & & & \\
\hline$[30-21]$ & 2 & $\mathrm{Cl}$ & 1 & & & & & $\mathrm{G}$ & & \\
\hline$[31-17]$ & 69 & C39 & 1 & & G & & & & & \\
\hline [32-29] & 1 & $\mathrm{Cl}$ & I & & & & & & & ST \\
\hline [34-22] & 2 & $\mathrm{Cl}$ & 2 & & & & & $\mathrm{RD}(2)$ & & \\
\hline [34-22] & 8 & $\mathrm{Cl}$ & I & & & & & $\mathrm{RD}^{\prime}$ & & \\
\hline [36-27] & 1 & $\mathrm{Cl}$ & 1 & $M$ & & & & & & \\
\hline [37-23] & 29 & 14 & 1 & FD & & & & & & \\
\hline [40-28] & 26 & $\mathrm{Cl}$ & 1 & & G & & & & & \\
\hline$[4 \mid-1]$ & 1 & $\mathrm{C} 9$ & 1 & C & & & & & & \\
\hline [58-64] & 35 & $\mathrm{Cl}$ & 1 & $M$ & & & & & & \\
\hline
\end{tabular}

1. Country: CZ Czech Republic, ES Spain, FL Finland, GR Greece, NL The Netherlands, NO Norway, SCO Scotland

2. Host: B badger (Meles meles), C cow (Bos taurus), CR crow (Corvus corone), F fox (Vulpes vulpes), FD fallow deer (Dama dama), G goat (Capra hircus), $\mathrm{H}$ hare (Lepus europaeus), J jackdaw (Corvus monedula), $\mathrm{M}$ moufflon (Ovis musimon), $\mathrm{R}$ rabbit (Oryctolagus cuniculus), RD red deer (Cervus elaphus), RK rook (Corvus frugilegus), S sheep (Ovis aries), ST stoat (Mustela erminea), W weasel (Mustela nivalis), WM wood mouse (Apodemus sylvaticus). The number of isolates obtained from each host species within a country is given in parenthesis.

3. Nomenclature as defined by Stevenson et al. 2002 [II]

4. Nomenclature as defined by Thibault et al. 2007 [56]

5. Nomenclature as defined by Pavlik et al. 1999 [50] 
son product-moment correlation between AFLP typing repeats was 85 to $90 \%$. Since the variation detected between repeat analyses was in the same range as the genetic variation detected between Map isolates it was concluded that AFLP could not discriminate effectively between isolates and no further Map isolates were typed using this procedure.

\section{MIRU-VNTR typing}

One hundred and forty seven Map isolates were typed by MIRU-VNTR and 23 different types were obtained (Table 1 and see supplementary dataset in Additional file 1). In addition, MIRU-VNTR types INMV 23 and 28 were obtained for the two IS901 positive M. avium isolates. The following MIRU-VNTR types were exhibited by Map isolates in this study: INMV $1(\mathrm{n}=75) ; 2(\mathrm{n}=35) ; 26(\mathrm{n}=9)$; $6(\mathrm{n}=4), 37(\mathrm{n}=3), 8,25,35(\mathrm{n}=2) ; 5,13,19,20,21$, $22,24,27,29,30,31,32,36,38,69(\mathrm{n}=1)$. INMV 1 and 2 were the most widely disseminated MIRU-VNTR types, both occurring in the Czech Republic, Finland, The Netherlands, Scotland and Spain (Table 1 and see supplementary dataset in Additional file 1 and Additional file 2: Table S1). INMV 1 also was found in Norway and INMV 2 in Greece (Table 1 and see supplementary dataset in Additional file 1 and Additional file 2: Table S1). The relative frequencies of the various alleles were calculated and are shown in Table 2 . The allelic diversity observed is consistent with the previous report [22].

\section{Comparison of typing techniques}

A predominance of one or two types was observed with all of the typing techniques and these predominant types could be further discriminated by one or both of the other typing methods (Table 3 ). For example, the predominant PFGE multiplex type [2-1] comprising 83 isolates was subdivided into nine different profiles by MIRU-VNTR and seven different profiles by BstEII IS900-RFLP. PFGE multiplex type [1-1] comprising 15 isolates could be subdivided into three INMV profiles and three BstEII IS900RFLP patterns. Minor multiplex profiles [2-30], [29-15] and [34-22] were each subdivided into two by MIRUVNTR. The major MIRU-VNTR type INMV1 consisting of 75 isolates was split by PFGE into 11 and by BstEII IS900RFLP into four subtypes. INMV2 composed of 35 isolates was subdivided into eight and seven types by PFGE and BstEII IS900-RFLP, respectively. The minor groups INMV $6,8,25,26$ and 35 were each subdivided by PFGE into a further two types and INMV 25 into two BstEII types. Both PFGE and MIRU-VNTR each differentiated the most widespread BstEII IS900-RFLP type C1, which included 71 isolates, into 14 and 11 distinct types, respectively. The BstEII type C17 comprising 49 isolates was subdivided into four types by each of the other typing methods. The minor types C5 and C9 were further subdivided into three and two, respectively, by PFGE and VNTR-MIRU subdivided C16 into two types. By combining PFGE and VNTR-MIRU or all three typing techniques it was possible to discriminate 37 and 44 patterns, respectively (Table 4 and see Additional file 2: Table S2).

\section{Genetic diversity}

Simpson's Index of Diversity (SID) with 95\% confidence intervals for the individual typing techniques and their combinations based on the analysis of 123 Map isolates for which results were obtained by the IS900-RFLP, PFGE and MIRU-VNTR methods are given in Table 4. SID values are given for the combined European dataset (all isolates), for the Scottish isolates and for the isolates from mainland Europe. When comparing SIDs, differences were considered statistically significant when there were no overlaps between the confidence intervals. The phylogenetic relationships between the isolates are shown in Figure 1 using PFGE data.

\section{Distribution among different host species}

Map isolates from three domestic species of ruminants and 14 different wildlife species, a feral cat and a captive giraffe were typed (Table 1 and see supplementary dataset in Additional file 1 and Additional file 2: Table S3). The wildlife encompassed both ruminant and non-ruminant species. Among the wildlife species, feral cat and captive giraffe, a total of nine IS900-RFLP, nine PFGE and six INMV types were detected.

In order to make a preliminary assessment of transmission dynamics, the combined typing data from all three molecular techniques was considered, as this was most discriminatory. A total of seven combined profiles were detected in isolates from more than one host species ([11], INMV1, C1; [1-1], INMV2, C1; [2-1], INMV1, C1; [21], INMV1, C17; [2-1], INMV2, C1; [2-19], INMV2, C5; [3-2], INMV1, C17) (Table 1). The evidence for interspecies transmission is more compelling if the same strain types are isolated from multiple species on the same property. Even with the limited data available on the properties from which the isolates in the study were obtained, it was possible to show that two combined profiles ([2-1], INMV1, C17 and ([2-19], INMV2, C5) were found in more than one species on the same property in seven cases (Table 5). Of these, four properties included isolates from both livestock and wildlife (EN, DR, I and R). The properties CF, DR and I, are all located within the geographical area of Perth and Kinross and EN, GE and R in the adjacent region of Angus in Scotland. Isolates from species on all six of these properties had the same combined profile ([2-1], INMV1, C17). Profile [2-19], INMV2, C5 was obtained from a goat and a sheep on the same property in Greece. 


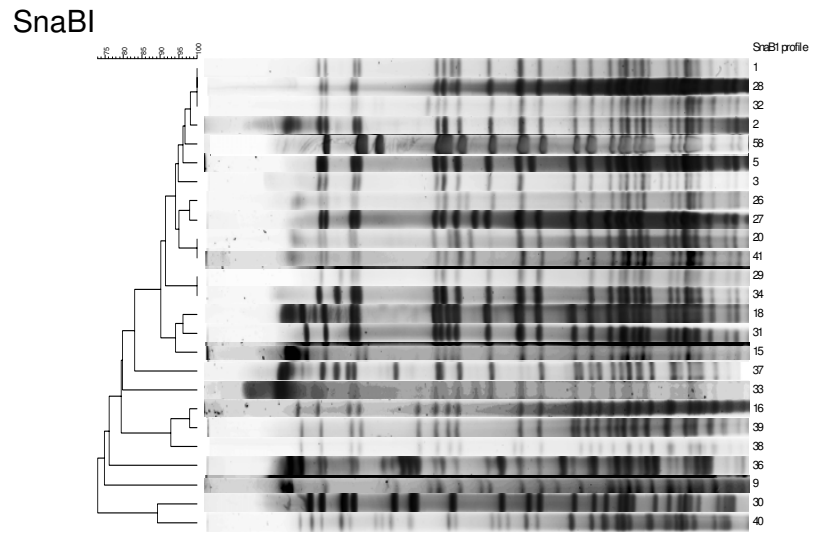

Spel

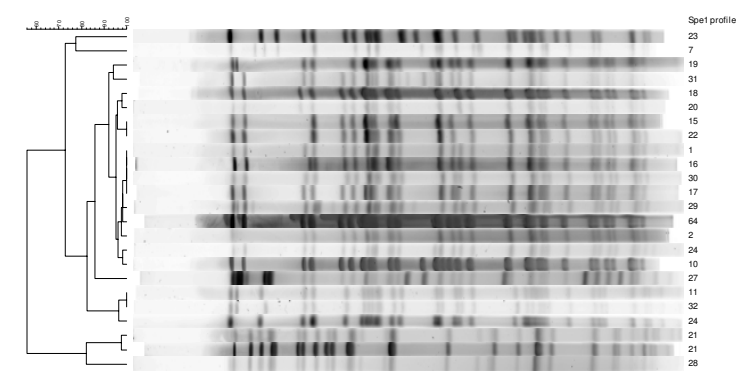

Figure I

Dendrograms showing the genetic relationships between the SnaBI and Spel PFGE profiles of the Map isolates analysed in the study. The similarity coefficients were calculated using Dice and hierarchical cluster analysis of the data was performed using the unweighted pair group method with arithmetic means.

Limited data was available for two properties in the Czech Republic, KRH and VO. On these properties the combined typing profiles of the isolates showed that they were not the same in all the species sampled. The PFGE multiplex profile [2-1] was found on $\mathrm{VO}$ in isolates from both a cow and a hare but IS900-RFLP analysis showed the hare isolate to have a different profile to the cow. The two deer on property KRH had a different profile to that of a cow on the same farm.

\section{Discussion}

The results of this study improve our knowledge of the epidemiology of paratuberculosis in Europe regarding the genetic diversity and distribution of Map isolates with respect to geographic location and host species of origin. The study has also permitted a comprehensive comparison of three standardized typing procedures, the results of which will inform future epidemiological studies as to the most appropriate and discriminative methods to employ.
This is the first study to compare the discriminatory power of IS900-RFLP, PFGE, AFLP and MIRU-VNTR for the molecular characterization of Map isolates. AFLP could not effectively discriminate between Map isolates and therefore is not suitable for epidemiological studies on paratuberculosis. A major problem with the technique was reproducibility. This was probably due in part to the variable quality of the mycobacterial DNA, which is highly dependent on growth phase and difficult to extract from Map isolates that are particularly resilient to lysis. Reproducibility could also have been affected by small variations in the experimental procedure such as shifts in electrophoretic mobility during capillary electrophoresis. Despite several attempts using alternative analytical procedures, no decrease in this variation could be obtained.

The most widely used measure of diversity is Simpson's Index of Diversity (SID), which we have employed here to estimate the discriminatory power of the various molecular typing techniques utilised in this study. When all Map isolates were considered irrespective of host or geographic origin, the SID was not significantly different between each of the individual typing techniques (IS900-RFLP, multiplex PFGE and MIRU-VNTR) and was low at a value between 0.636 and 0.664 in accordance with previous reports $[23,24]$. The SID value is strongly influenced by the distribution of types rather than the number of types detected. This is clearly demonstrated by comparing the two methods with the largest difference in the number of patterns detected i.e. IS900-RFLP, which identified 15 profiles and multiplex PFGE, which detected 26 profiles. Despite the number of profiles detected, both methods have almost the same SID point estimate and 95\% confidence interval. The SID for IS900-RFLP could have been improved further had it been possible to obtain PstI profiles for the isolates. The discriminatory power of the individual techniques is too low for epidemiological surveys since a SID of around 0.9 is generally considered the minimum. For isolates from mainland Europe, SID for the combination of multiplex PFGE and MIRU-VNTR, with or without IS900-RFLP, exceeded the threshold value of 0.9. The increase in SID is not surprising since the different typing techniques target different sources of genetic variation and have different limitations and will therefore complement each other when used in combination. Due to limited heterogeneity among Scottish isolates, combining all three typing techniques increased SID to 0.879 for the dataset as a whole, providing discriminatory power close to the minimum but not quite reaching the target value.

Although the combination of all three typing techniques gives the greatest discrimination, this is generally not practical or cost effective for large national or international 
Table 2: MIRU-VNTR Allelic diversity among the Map isolates.

\begin{tabular}{|c|c|c|c|c|c|c|c|c|c|c|c|c|}
\hline \multicolumn{13}{|c|}{ No. of isolates with specified MIRU copy No. } \\
\hline Locus & 0 & $\mathbf{I}$ & 2 & 3 & 4 & 5 & 6 & 7 & 8 & 9 & 10 & Allelic diversity (h) \\
\hline 292 & & & 14 & 47 & 80 & 3 & 2 & & I & & & 0.58 \\
\hline 10 & & 21 & 126 & & & & & & & & & 0.24 \\
\hline 7 & & 10 & 128 & 9 & & & & & & & & 0.22 \\
\hline 3 & 10 & 6 & 131 & & & & & & & & & 0.2 \\
\hline 25 & & 2 & & 138 & & 7 & & & & & & 0.1 \\
\hline$\times 3$ & & 6 & 139 & 2 & & & & & & & & 0.09 \\
\hline 47 & & & 1 & 142 & 4 & & & & & & & 0.06 \\
\hline 32 & & & & & & & & & 146 & 1 & & 0.006 \\
\hline
\end{tabular}

The allelic diversity $(\boldsymbol{h})$ at a locus was calculated as $\boldsymbol{h}=\mathrm{I}-\Sigma \mathbf{x}_{i}^{2}[\boldsymbol{n} /(\boldsymbol{n}-\mathrm{I})]$, where $\boldsymbol{x}_{i}$ is the frequency of the ith allele at the locus, and $\boldsymbol{n}$ the number of isolates [52,53].

studies and often a compromise is sought. The choice of typing method will be influenced by the predominant isolate type in the population to be tested. This is highlighted in this study by considering the data shown in Table 4 for the isolates from Scotland versus those from mainland Europe and the combined European dataset (i.e. all isolates). The isolates from Scotland comprise a homogeneous population in which the B-C17 IS900-RFLP profile predominates and is therefore a rigorous test for the combination approach. Comparing the SIDs for the various combinations of typing techniques there was no difference between multiplex PFGE + MIRU-VNTR and the combination of all three typing techniques. Therefore, a combination of multiplex PFGE + MIRU-VNTR would be suitable for epidemiological studies in Scotland. A combination of multiplex PFGE + MIRU-VNTR would also be appropriate for mainland Europe but here a combination of IS900-RFLP and multiplex PFGE would also perform well. The best combination for the combined European dataset was all three typing techniques. The SID for the isolates from mainland Europe was often higher than that for the combined European dataset, the latter being affected by the inclusion of the less heterogeneous Scottish isolates. Based on these results a small pilot study of

Table 3: Subdivision of the predominant types by the different typing techniques.

\begin{tabular}{|c|c|c|c|c|}
\hline \multirow[t]{2}{*}{ Type } & \multirow[t]{2}{*}{ No. of isolates } & \multicolumn{3}{|c|}{ Subdivided by } \\
\hline & & BstEII RFLP2 & PFGE $^{3}$ & MIRU-VNTR 4 \\
\hline$[2-1]$ & 83 & $\mathrm{Cl}, \mathrm{C} 5, \mathrm{C} 9, \mathrm{Cl}, \mathrm{Cl}, \mathrm{C} 36, \mathrm{C} 38$ & & $\mathrm{I}, 2,5,8,19,22,24,25,30$ \\
\hline$[1-1]$ & 15 & $\mathrm{Cl}, \mathrm{C} 5, \mathrm{Cl} 8$ & & I, 2, 6 \\
\hline [29-15] & 4 & $\mathrm{Cl}$ & & 36,37 \\
\hline [34-22] & 4 & $\mathrm{Cl}$ & & 2,8 \\
\hline$[2-30]$ & 2 & $\mathrm{Cl} 6$ & & 25,1 \\
\hline INMV I & 75 & $\mathrm{Cl}, \mathrm{C} 9, \mathrm{Cl} 6, \mathrm{Cl} 7$ & $\begin{array}{l}{[1-1],[2-1],[2-10],[2-30],[3-2],[5-2],} \\
{[20-1],[32-29],[33-20],[36-27],[41-1]}\end{array}$ & \\
\hline INMV 2 & 35 & $\mathrm{Cl}, \mathrm{C} 5, \mathrm{Cl} 7, \mathrm{Cl}, \mathrm{C} 22, \mathrm{C} 27, \mathrm{C} 36$ & $\begin{array}{l}{[1-1],[2-1],[2-17],[2-19],[2-31],[27-18],} \\
{[30-2 \mid],[34-22]}\end{array}$ & \\
\hline INMV 26 & 9 & $\mathrm{Cl}$ & {$[15-25],[40-28]$} & \\
\hline INMV 6 & 4 & $\mathrm{Cl}$ & {$[I-I],[2-2 \mid]$} & \\
\hline INMV 25 & 2 & $\mathrm{Cl} 6, \mathrm{Cl} 7$ & {$[2-1],[2-30]$} & \\
\hline INMV 8 & 2 & $\mathrm{Cl}$ & {$[2-1],[34-22]$} & \\
\hline INMV 35 & 2 & $\mathrm{Cl}$ & {$[26-I],[58-64]$} & \\
\hline $\mathrm{Cl}$ & 71 & & $\begin{array}{l}{[1-1],[2-1],[2-10],[15-16],[15-25],[18-} \\
1],[20-1],[26-1],[29-15],[30-21],[34- \\
22],[36-27],[40-28],[58-64]\end{array}$ & $\mathrm{I}, 2,6,8,13,24,26,35,36,37,38$ \\
\hline $\mathrm{CI7}$ & 49 & & {$[2-1],[3-2],[5-2],[32-29]$} & $1,2,19,25$ \\
\hline $\mathrm{C5}$ & 5 & & {$[1-1],[2-1],[2-19]$} & 2 \\
\hline C9 & 3 & & {$[2-I],[4 I-I]$} & 1 \\
\hline $\mathrm{Cl} 6$ & 2 & & {$[2-30]$} & I, 25 \\
\hline
\end{tabular}

I. 123 Map isolates were typed by IS900-RFLP, PFGE and MIRU-VNTR but not all isolates were typed by all three typing procedures.

2. Nomenclature as defined by Pavlik et al. 1999 [50]

3. Nomenclature as defined by Stevenson et al. (2002) [II]

4. INMV numbers as defined by INRA Nouzilly MIRU-VNTR [56] 
Table 4: Simpson's index of diversity (SID) with $95 \%$ confidence interval for individual and combined typing methods

\begin{tabular}{|c|c|c|c|c|c|c|}
\hline \multirow[b]{2}{*}{ Method } & \multicolumn{2}{|c|}{ All isolates } & \multicolumn{2}{|c|}{ Scotland } & \multicolumn{2}{|c|}{ Mainland Europe } \\
\hline & No. of types & SID & No. of types & SID & No. of types & SID \\
\hline PFGE-SnaBI & 21 & $0.594(0.493-0.695)^{\mathrm{a}}$ & 5 & $0.234(0.075-0.393)^{\mathrm{ab}}$ & 17 & $0.744(0.655-0.834)^{a c}$ \\
\hline PFGE-Spel & 19 & $0.485(0.372-0.597)^{\mathrm{a}}$ & 5 & $0.267(0.105-0.430)^{\mathrm{ab}}$ & 16 & $0.599(0.468-0.729)^{a b}$ \\
\hline PFGE-multiplex & 26 & $0.654(0.558-0.749)^{\mathrm{ab}}$ & 6 & $0.270(0.104-0.437)^{\mathrm{ab}}$ & 22 & $0.804(0.727-0.88 I)^{\text {acd }}$ \\
\hline IS900-RFLP & 15 & $0.636(0.582-0.690)^{\mathrm{a}}$ & 3 & $0.080(0.00-0.191)^{\mathrm{a}}$ & 14 & $0.422(0.277-0.567)^{\mathrm{b}}$ \\
\hline MIRU-VNTR & 19 & $0.664(0.588-0.740)^{\mathrm{ab}}$ & 5 & $0.235(0.074-0.395)^{\mathrm{ab}}$ & 16 & $0.770(0.706-0.835)^{a c}$ \\
\hline $\begin{array}{l}\text { Multiplex PFGE + IS900- } \\
\text { RFLP }\end{array}$ & 34 & $0.834(0.782-0.885)^{c}$ & 6 & $0.270(0.104-0.437)^{\mathrm{ab}}$ & 30 & $0.877(0.82-0.934)^{\text {cde }}$ \\
\hline $\begin{array}{l}\text { Multiplex PFGE + MIRU- } \\
\text { VNTR }\end{array}$ & 37 & $0.797(0.727-0.867)^{\mathrm{bc}}$ & 9 & $0.406(0.228-0.584)^{\mathrm{ab}}$ & 30 & $0.914(0.878-0.949)^{\mathrm{de}}$ \\
\hline $\begin{array}{l}\text { IS900-RFLP + MIRU- } \\
\text { VNTR }\end{array}$ & 29 & $0.825(0.774-0.876)^{c}$ & 6 & $0.236(0.074-0.398)^{\mathrm{ab}}$ & 24 & $0.868(0.820-0.917)^{\text {cde }}$ \\
\hline All methods combined & 44 & $0.879(0.83 \mathrm{I}-0.927)^{\mathrm{c}}$ & 9 & $0.406(0.228-0.584)^{b}$ & 36 & $0.941(0.913-0.969)^{\mathrm{e}}$ \\
\hline
\end{tabular}

Simpson's index of diversity (SID) with $95 \%$ confidence interval for individual and combined typing methods based on analysis of I 23 Map isolates originating from Scotland $(n=48)$ and mainland Europe $(n=75)$ abcde Non-overlapping $95 \%$ confidence intervals are considered significantly different [55] and are indicated by different superscripts.

the population of interest is recommended before undertaking a large epidemiological survey. For further epidemiological studies in Scotland, it would be advantageous to undertake a pilot study including short sequence repeat analysis [25], which may improve the discriminatory power for this homogeneous population of isolates.

The study identified the common isolate types within the European countries examined. IS900-RFLP profile C1 was the most widespread, consistent with previous reports from individual countries [26-31]. This profile has a global distribution, being found in the United States, Australia and New Zealand [10,30,32]. Although IS900-RFLP profile $\mathrm{C} 17$ is commonly isolated in Scotland it is reported to be relatively rare in other European countries $[30,31]$. It was identified in isolates from The Netherlands and Norway in this study and has been reported previously in Germany [31] and is predominant in specific regions of Argentina [30,33]. The most common PFGE profile was [2-1] found in six of the seven countries examined, closely followed by [1-1] found in four. INVM 2 was

Table 5: Map strain types infecting multiple host species on a single property

\begin{tabular}{lll}
\hline Property & Typing profile & Species \\
\hline EN & {$[2-1]$ INMVI CI7 } & Cow, hare, rabbit, rook, stoat \\
CF & {$[2-1]$ INMVI CI7 } & Crow, fox, rabbit (5) \\
DR & {$[2-1]$ INMVI CI7 } & Cow, rabbit (4), woodmouse \\
GE & {$[2-1]$ INMVI CI7 } & Fox, stoat (2), weasel \\
I & {$[2-1]$ INMVI CI7 } & Rabbit, sheep \\
R & {$[2-1]$ INMVI CI7 } & Cow, rabbit \\
KV & {$[2-19]$ INMV2 C5 } & Goat, sheep
\end{tabular}

Numbers in parenthesis indicate the number of animals of that species identified with the given typing profile found in six countries and INVM 1 in five. Further investigations will be required to determine if this distribution is a consequence of animal movements, increased virulence or whether these isolates have characteristics that allow them to transmit more readily. There is evidence to suggest that different mycobacterial strain types vary in their ability to cause disease. Caws et al. [34] provided evidence that M. tuberculosis genotype influences clinical disease phenotype and demonstrated a significant interaction between host and bacterial genotypes and the development of tuberculosis. Gollnick et al. [35] reported that the survival of Map in bovine monocyte-derived macrophages was not affected by host infection status but by the infecting strain type. Two recent studies suggest that different Map strain types may play a role in polarizing the host immune responses during infection [36,37]. Also, different Map strains have been found to differ in virulence in experimental infections of deer [38] and in a mouse model (KS, unpublished data) and Verna et al. have provided data to show how the strain type may influence the pathology of ovine paratuberculosis [39].

Surprisingly, no Type I strains (corresponding to S Type strains in the literature [40]) were identified within the 27 sheep and 33 goat field isolates submitted by the partners. This may be a reflection of the difficulties encountered in isolating and growing these strains in vitro. Typically, isolates of strain Type I are slow-growing, taking longer than 16 weeks and sometimes as long as 18 months to isolate on solid medium. Cultures are often not retained this long in diagnostic laboratories. Furthermore, studies have shown that the decontamination procedures or media used for isolation can significantly affect recovery of these strains. Reddacliff et al. [41] reported the detrimental effects of various decontamination protocols on the 
recovery of Type I strains from tissues and faeces. The addition of egg yolk and mycobactin J to BACTEC 12B or $7 \mathrm{H} 9$ broth was found to be essential for the isolation of Australian sheep strains from faeces and to enhance their recovery from tissue samples [42]. Other workers have successfully isolated Type I or III strains on LJ or Middlebrook 7H11 supplemented with mycobactin J [43,44]. The addition of antibiotics can also affect growth. Both ampicillin and vancomycin hydrochloride can retard growth of Type I strains [45]. The various laboratories participating in this study used a range of decontamination procedures and culture media but it is not possible to rule out a culture bias.

The results of this survey highlight an interesting difference between the epidemiology of Map in Europe and Australia. This study shows that in Europe, Type II strains (corresponding to C Type strains in the literature [10]) are commonly isolated from sheep, goats and cattle whereas in Australia, Type II strains are rarely, if ever, isolated from sheep -the predominant type being Type I. We can only speculate as to the reasons for this difference. Management practices will affect the circulation of strains and can differ between some parts of Europe and Australia. The scale of farming operations and relative proportions of the different livestock co- or sequentially grazing may also be a factor. Paratuberculosis is more common in sheep in Australia than in cattle and the Type I strain is more virulent for sheep than cattle [39].

In this study, Map was isolated from 19 different host species, which included both ruminants and non-ruminants. This is the first report of the isolation of Map from a giraffe. The Type II strains appear to have greater propensity for infecting a broad range of host species whereas the epidemiological data available for Type I strains suggests that they have a preference for sheep and goats [23]. Since our results show that the same profiles are found in isolates from different species, it strongly suggests that strain sharing occurs. Even more convincing was the observation that the same profiles were isolated from wildlife species and domestic ruminants on the same farm. The frequency or ease with which interspecies transmission occurs are unknown entities and require further investigation. Similarly, the relative risk of transmission from domestic livestock to wildlife or vice versa remains to be determined.

All animals in contact with Map contaminated faeces on an infected property will contribute to the spread of disease through passive transmission. However, Map infects a variety of wildlife host species that potentially could be reservoirs for infection of domestic livestock and have serious implications for control of paratuberculosis. The role of wildlife reservoirs in the epidemiology of paratuberculosis will depend on a number of factors which need to be taken into consideration when undertaking a risk assessment for interspecies transmission. Although Map can infect many wildlife species, only wild ruminants and lagomorphs show evidence of disease as determined by the presence of gross or microscopic lesions with associated acid fast bacteria [46]. These wildlife species have the capacity to excrete Map and spread disease to other susceptible species primarily through further faecal contamination of the environment. Potentially, they could constitute wildlife reservoirs. By definition, to constitute a wildlife reservoir the infection would need to be sustained within the species population. Evidence is available for vertical, pseudovertical and horizontal transmission within natural rabbit populations which could contribute to the maintenance of Map infections within such populations $[47,48]$.

The other wildlife species in this study could be categorised into predators and scavengers that probably acquire the disease through eating contaminated prey or carrion, respectively. It has been reported previously that these animals show no clinical signs of disease and only minor histopathological changes with a few acid fast bacteria in tissues [4,5]. Such infected predators and scavengers are probably 'dead-end hosts' and are not high risk factors for interspecies transmission.

Information pertaining to strain types can assist in designing and evaluating disease control programmes. It is beneficial to know the predominant strain type in a population or the virulence of a particular strain type particularly for developing new vaccines. Singh et al. [49] recently reported the effectiveness and advantage of using a vaccine based on a local 'bison-type' strain.

\section{Conclusion}

In conclusion, this survey has helped to expand our knowledge to improve our understanding of the epidemiology of paratuberculosis. It is hoped that the information provided will facilitate future surveys and research strategies to resolve the outstanding epidemiological questions regarding this disease.

The results of this study were in agreement with previous reports indicating that Map isolates comprise a relatively homogeneous population exhibiting little genetic diversity compared with other bacterial pathogens. As a result it is necessary to use multiple genotyping techniques targeting different sources of genetic variation to obtain the level of discrimination necessary to investigate transmission dynamics and trace the source of infections. Identical genotypes were obtained from Map isolated from different host species co-habiting on the same property strongly suggesting that interspecies transmission occurs. Interspecies transmission of Map between wildlife species and 
domestic livestock on the same farm provides further evidence to support a role for wildlife reservoirs of infection. However, in assessing the relative risk of transmission between wildlife and domestic livestock, distinction needs to be made between passive and active transmission as well as the potential for contact.

\section{Methods \\ Bacteria}

A total of 166 suspected Map isolates were obtained from the Czech Republic $(n=27)$, Finland $(n=5)$, Greece $(n=$ $6)$, The Netherlands $(n=46)$, Norway $(n=7)$, Scotland ( $n$ $=54)$ and Spain $(\mathrm{n}=21)$ (Table 1 and see supplementary dataset in Additional file 1). The isolates from livestock species were obtained from animals showing symptoms of paratuberculosis and from various clinical samples (see supplementary dataset in Additional file 1) that were submitted to the various laboratories for diagnosis. In the case of isolates from wildlife species, these were isolated from wildlife on properties with a known history or current problem with paratuberculosis and these animals did not necessarily show any clinical signs. The isolates were cultured from 19 different host species (supplementary dataset in Additional file 1 and Additional file 2: Table S3). Isolates were propagated on slopes of one of the following media depending on what was used routinely in the supply laboratories:- modified Middlebrook 7H11 supplemented with $20 \%$ (vol/vol) heat-inactivated newborn calf serum, $2.5 \%$ (vol/vol) glycerol, $2 \mathrm{mM}$ asparagine, $10 \%$ (vol/vol) Middlebrook oleic acid-albumindextrose-catalase (OADC) enrichment medium (Becton Dickinson, Oxford, Oxfordshire, United Kingdom), Selectatabs (code MS 24; MAST Laboratories Ltd., Merseyside, United Kingdom), and $2 \mu \mathrm{g} \mathrm{ml}^{-1}$ mycobactin J (Allied Monitor, Fayette, Mo.); Herrold's egg yolk medium with 2 $\mu \mathrm{g} \mathrm{ml}{ }^{-1}$ mycobactin J or Lowenstein-Jensen medium with $2 \mu \mathrm{g} \mathrm{ml}^{-1}$ mycobactin J. For the typing panel, three Map isolates were included to represent the three strain types described in Map $[11,12]$. In addition, three isolates (one bovine, one ovine and one caprine) were duplicated in the panel as internal controls for the reproducibility of the typing methods and M. bovis BCG, M. phlei and IS901 positive $M$. avium (it is not known if this isolate is $M$. avium subsp. avium or M. avium subsp. silvaticum) were included as negative controls. The isolates were coded with an EU reference number (see supplementary dataset in Additional file 1) and genotyped in a blind study.

\section{IS900-RFLP method}

The typing laboratories were provided either with cultures or with DNA in agarose plugs that had been prepared for PFGE typing. DNA extraction from cultures and IS900RFLP analysis was performed using the standardized procedure published by Pavlik et al. [50]. Where plugs were provided, the restriction digests were carried out in the presence of agarose as described for PFGE [51]. Briefly, a 3-5 $\mathrm{mm}$ insert of agarose was cut from the plug, washed extensively in TE buffer and pre-incubated with the appropriate restriction buffer containing $0.1 \mathrm{mg} \mathrm{ml}^{-1} \mathrm{BSA}$. After one hr the buffer was discarded and replaced with fresh buffer containing the restriction endonuclease and incubated overnight at $37^{\circ} \mathrm{C}$. The agarose containing the digested DNA was then loaded into the wells of an agarose gel as described in the standardized procedure [51]. New profiles were designations assigned by the National Veterinary Institute, Brno using the standard nomenclature described. Profiles were analysed using Gel Compar (Biomathematics, Belgium).

\section{PFGE analysis}

PFGE analysis was carried out using SnaBI and SpeI according to the published standardized procedure of Stevenson et al. [11] with the following modifications. Plugs were prepared to give a density of $1.2 \times 10^{10}$ cells ml-1 and the incubation time in lysis buffer was increased to $48 \mathrm{hr}$. The concentration of lysozyme was increased to $4 \mathrm{mg} \mathrm{ml}^{-}$ 1. Incubation with proteinase $\mathrm{K}$ was carried out for a total of seven days and the enzyme was refreshed after four days. Restriction endonuclease digestion of plug DNA by SpeI was performed with $10 \mathrm{U}$ overnight in the appropriate restriction endonuclease buffer supplemented with $0.1 \mathrm{mg} \mathrm{ml}^{-1} \mathrm{BSA}$, after which the enzyme was refreshed and incubated for a further $6 \mathrm{hr}$. The parameters for electrophoresis of SpeI restriction fragments were changed to separate fragments of between 20 and $250 \mathrm{~Kb}$ as determined by the CHEF MAPPER and electrophoresis was performed for $40 \mathrm{hr}$. The modified conditions are available on the website [51]. Gel images were captured using an AlphaImager 2200 (Alpha Innotech). Profiles were analysed using Bionumerics Maths ${ }^{\mathrm{TM}}$ software (Applied Maths, Belgium).

\section{AFLP analysis}

A loop of cells from a culture tube was resuspended in 1 $\mathrm{ml} \mathrm{H}_{2} \mathrm{O}$. The optical density was adjusted to $1 \mathrm{McFarland}$ unit in order to standardize the performance of the subsequent DNA extraction. DNA was extracted using Instagene Matrix (Bio-Rad ${ }^{\mathrm{TM}}$ ) according to the manufacturer's instructions.

$100 \mathrm{ng}$ template DNA was digested for $2 \mathrm{hr}$ with 1 unit EcoRI and MseI at $37^{\circ} \mathrm{C}$. The $10 \mu \mathrm{l}$ mixture contained: 5 $\mu$ template DNA, $1.0 \mu \mathrm{l}(10 \times) \mathrm{BSA}, 1.0 \mu \mathrm{l}$ NEB 2 buffer, $0.05 \mu \mathrm{l}$ EcoRI, $0.1 \mu \mathrm{l}$ Mse I (NEB) and $\mathrm{H}_{2} \mathrm{O}$ and was incubated for $2 \mathrm{hr}$ at $37^{\circ} \mathrm{C}$.

Eco-adaptor (50 pmol $\mu^{-1}$ ), annealed from primer pair: 5'-ctcgtagactgcgtacc-3' and 5'-aattggtacgcagtctac-3'and Mse-adaptor (5 pmol $\left.\mu \mathrm{l}^{-1}\right)$ annealed from primer pair: 5'gacgatgagtcctgag-3'and 5 '-tactcaggactcatc-3' were ligated 
to the digested DNA by adding $5 \mu$ l of the ligation mixture (0.6 $\mu$ l Eco-adaptor, $0.6 \mu \mathrm{l}$ Mse-adaptor, $0.3 \mu \mathrm{l}$ T4-ligase (NEB, 1 unit), $1.5 \mu \mathrm{l} 5 \mathrm{M} \mathrm{NaCl}, 1.5 \mu$ ligase buffer $(10 \times)$ (NEB) and $0.5 \mu \mathrm{l} \mathrm{H}_{2} \mathrm{O}$ ) to $10 \mu \mathrm{l}$ of the RE-digestion mixture, followed by $2 \mathrm{hr}$ incubation at $16^{\circ} \mathrm{C}$.

The amplification reaction was carried out in a $10 \mu \mathrm{l} \mathrm{mix-}$ ture containing 5.0 $\mu \mathrm{l}$ DNA from the adaptor-ligation reaction, $1.2 \mu \mathrm{l} \mathrm{H}_{2} \mathrm{O}, 0.2 \mu \mathrm{d} \mathrm{dNTP}(10 \mathrm{mM}), 1.0 \mu \mathrm{l} \mathrm{PCR}$ buffer (10× PCR buffer II, ABI), $0.6 \mu \mathrm{IgCl}_{2}(25 \mathrm{mM}), 1.2$ $\mu$ l Mse-0 primer (50 ng $\mu^{-1}$ ) and $0.2 \mu \mathrm{l}$ Amplitaq Taq polymerase $(5 \mathrm{U})$. The PCR cycling conditions were: hold 2 min $72^{\circ} \mathrm{C}, 12$ cycles: $\left(30 \mathrm{sec}, 65^{\circ} \mathrm{C}\right.$ touch down $0.7 \mathrm{C}$ per cycle, $60 \mathrm{sec} 72^{\circ} \mathrm{C}$ ), 23 cycles: (30 sec, $56 \mathrm{C}$, $60 \mathrm{sec}$, $72^{\circ} \mathrm{C}$ ), $60 \mathrm{sec}, 72^{\circ} \mathrm{C}$, hold $4^{\circ} \mathrm{C}$.

The PCR product was run on a capillary automated sequencer (ABI 3100 avant). The AFLP profiles were analysed with the Bionumerics software programme (Applied Maths).

\section{MIRU-VNTR analysis}

DNA in agarose plugs prepared for PFGE analysis was used for MIRU-VNTR analysis. Small pieces of agarose plug, approximately $2 \mathrm{~mm}$ thick, were washed in TE buffer ( $\mathrm{pH} 8)$ to remove residual EDTA in the storage buffer. One hundred microlitres of TE buffer were added to the agarose and the sample boiled for $10 \mathrm{~min}$ to melt the agarose and denature the DNA. Five microlitres (80 ng) were used for PCR and the MIRU-VNTR analysis was performed as described by Thibault et al. [22] detecting eight polymorphic loci. The allelic diversity $(h)$ at a locus was calculated as $h=1-\Sigma x_{i}^{2}[n /(n-1)]$, where $x_{i}$ is the frequency of the $i$ th allele at the locus, and $n$ the number of isolates $[52,53]$.

\section{Strain type analysis by PCR}

Isolates were typed to differentiate between strain types I or II using the PCR reported by Dohmann et al. (2003)[17].

\section{Calculation of the discriminatory power}

Simpson's index of diversity (SID) described by Hunter and Gaston [54] was used as a numerical index for the discriminatory power of PFGE, IS900-RFLP and VNTR and combinations of these typing methods. The SID was calculated using the data from 123 isolates that were typed with all three typing procedures using the following formula:

$$
D I=1-\left[\frac{1}{N(N-1)} \sum_{j=1}^{s} n_{j}\left(n_{j}-1\right)\right]
$$

Where $N$ is the total number of isolates in the typing scheme, $s$ is the total number of distinct patterns discriminated by each typing method and strategy, and $n_{j}$ is the number of isolates belonging to the $j$ th pattern. Confidence intervals of $95 \%$ were calculated according to Grundmann et al. [55].

\section{Authors' contributions}

KS conceived of the study, participated in its design and coordination, collated and analysed the data and drafted the manuscript. JA, SD, ZD, KD, IH, LDJ, MK, LM, IP, VT, PW participated in the laboratory and field work. FB, IH, PW and RZ participated in analyzing the data. GFG, DB, JMS, AG participated in the conception, design and coordination of the study. All authors read, criticized and approved the final manuscript.

\section{Additional material}

\section{Additional file 1}

Complete dataset. Complete dataset with information on host species of origin, clinical sample used for isolation, geographical location and typing data for individual isolates included in the study.

Click here for file

[http://www.biomedcentral.com/content/supplementary/1471-

2180-9-212-S1.XLS]

\section{Additional file 2}

Supplementary tables listing the genotypes obtained with the combined typing techniques of IS900-RFLP, PFGE and MIRU-VNTR and documenting the distribution of Map molecular types according to geographical location and host species.

Click here for file

[http://www.biomedcentral.com/content/supplementary/1471-

2180-9-212-S2.PDF]

\section{Acknowledgements}

The authors would like to thank Finn Saxegaard and Tone Bjordal Johansen (National Veterinary Institute, Oslo, Norway) and Professor Sinikka Pelkonen (National Veterinary and Food Institute, EELA, Kuopio, Finland) for supplying isolates and Dennis Henderson (Scottish Agricultural College, Perth, Scotland) for technical assistance. The work was funded by the European Commission (Contract Nos QLK2-CT-200I-01420 and QLK2-CT200 I-0879). KS, SD, IH, LM and RZ were funded by the Scottish Government Rural and Environment Research and Analysis Directorate, FB and VT were supported by the Institut National de la Recherche Agronomique and Agence Française de Sécurité Sanitaire des Aliments (contract I46 AIP P00297) and IP and MK by the Ministry of Agriculture of the Czech Republic (grant No. MZE 0002716202).

\section{References}

I. Kennedy DJ, Benedictus G: Control of Mycobacterium avium subsp. paratuberculosis infection in agricultural species. Rev Sci Tech Off Int Epiz 200I, 20:15I-179.

2. Nielsen SS, Toft N: A review of prevalences of paratuberculosis in farmed animals in Europe. Prev Vet Med 2009, 88: I- I4. 
3. Greig A, Stevenson K, Henderson D, Perez V, Hughes V, Pavlik I, Hines ME, McKendrick I, Sharp JM: Epidemiological study of paratuberculosis in wild rabbits in Scotland. J Clin Microbiol |999, 37:|746-|75|

4. Beard PM, Henderson D, Daniels MJ, Pirie A, Buxton D, Greig A, Hutchings MR, McKendrick I, Rhind S, Stevenson K, Sharp JM: Evidence of paratuberculosis in fox (Vulpes vulpes) and stoat (Mustela erminea). Vet $\operatorname{Rec} 1999,145: 612-613$.

5. Beard PM, Daniels MJ, Henderson D, Pirie A, Rudge K, Buxton D, Rhind S, Greig A, Hutchings MR, McKendrick I, Stevenson K, Sharp $\mathrm{JM}$ : Paratuberculosis infection of non-ruminant wildlife in Scotland. I Clin Microbiol 2001, 39:1517-152I.

6. Feller M, Huwiler K, Stephan R, Altpeter E, Shang A, Furrer H, Pfyffer $\mathrm{GE}$, Jemmi T, Baumgartner A, Egger M: Mycobacterium avium subspecies paratuberculosis and Crohn's disease: a systematic review and meta-analysis. Lancet Infect Dis 2007, 7:607-6I3.

7. Nacy C, Buckley M: Mycobacterium avium paratuberculosis: Infrequent human pathogen or public health threat? In Report from the American Academy for Microbiology American Academy for Microbiology, Washington, DC; 2008.

8. Turenne CY, Collins DM, Alexander DC, Behr MA: Mycobacterium avium subsp. paratuberculosis and $M$. avium subsp. avium are independently evolved pathogenic clones of a much broader group of M. avium organisms. J Bacteriol 2008, 190:2479-2487.

9. Collins DM, Gabric DM, de Lisle GW: Identification of two groups of Mycobacterium paratuberculosis strains by restriction endonuclease analysis and DNA hybridization. J Clin Microbiol 1990, 28:1591-1596.

10. Whittington RJ, Hope AF, Marshall DJ, Taragel CA, Marsh I: Molecular epidemiology of Mycobacterium avium subsp. paratuberculosis: IS900 restriction fragment length polymorphism and IS I 3 I I polymorphism analyses of isolates from animals and a human in Australia. J Clin Microbiol 2000, 38:3240-3248.

II. Stevenson K, Hughes VM, de Juan L, Inglis NF, Wright F, Sharp JM: Molecular characterization of pigmented and nonpigmented isolates of Mycobacterium avium subsp. paratuberculosis. J Clin Microbiol 2002, 40: 1798-1804.

12. de Juan L, Mateos A, Dominguez L, Sharp J, Stevenson K: Genetic diversity of Mycobacterium avium subspecies paratuberculosis isolates from goats detected by pulsed-field gel electrophoresis. Vet Microbiol 2005, I 06:249-257.

13. Castellanos E, Aranaz A, Romero B, de Juan L, Alvarez J, Bezos J, Rodriguez $S$, Stevenson K, Mateos A, Dominguez L: Polymorphisms in gyrA and gyrB genes among Mycobacterium avium subspecies paratuberculosis Type I, II, and III isolates. I Clin Microbiol 2007, 45:3439-3442

14. Whittington R, Marsh I, Choy E, Cousins D: Polymorphisms in ISI3II, an insertion sequence common to Mycobacterium avium and $M$. avium subsp. paratuberculosis, can be used to distinguish between and within these species. Mol Cell Probes 1998, I 2:349-358.

I5. Whittington RJ, Marsh IB, Whitlock RH: Typing of IS I3 I I polymorphisms confirms that bison (Bison bison) with paratuberculosis in Montana are infected with a strain of Mycobacterium avium subsp. paratuberculosis distinct from that occurring in cattle and other domesticated livestock. Mol Cell Probes 200I, I 5: I39-I45.

16. Collins DM, De Zoete M, Cavaignac SM: Mycobacterium avium subsp. paratuberculosis strains from cattle and sheep can be distinguished by a PCR test based on a novel DNA sequence difference. J Clin Microbiol 2002, 40:4760-4762.

17. Dohmann K, Strommenger B, Stevenson K, de Juan L, Stratmann J, Kapur V, Bull TJ, Gerlach GF: Characterization of genetic differences between Mycobacterium avium subsp. paratuberculosis Type I and Type II isolates. J Clin Microbiol 2003, 4I:52 I5-5223.

18. Griffiths TA, Rioux K, De Buck J: Sequence polymorphisms in a surface PPE protein distinguish types I, II, and III of Mycobacterium avium subsp. paratuberculosis. J Clin Microbiol 2008, 46: $1207-1212$.

19. Marsh IB, Whittington RJ: Deletion of an $\mathbf{m m p} \mathbf{L}$ gene and multiple associated genes from the genome of the $S$ strain of Mycobacterium avium subsp. paratuberculosis identified by representational difference analysis and in silico analysis. Mol Cell Probes 2005, 19:371-384.

20. Semret M, Turenne CY, de Haas P, Collins DM, Behr MA: Differentiating host-associated variants of Mycobacterium avium by
PCR for detection of large sequence polymorphisms. J Clin Microbiol 2006, 44:88I-887.

21. Marsh IB, Bannantine JP, Paustian ML, Tizard ML, Kapur V, Whittington RJ: Genomic comparison of Mycobacterium avium subsp. paratuberculosis sheep and cattle strains by microarray hybridization. J Bacteriol 2006, I 88:2290-2293.

22. Thibault VC, Grayon M, Boschiroli ML, Hubbans C, Overduin P, Stevenson K, Gutierrez MC, Supply P, Biet F: New variable-number tandem-repeat markers for typing Mycobacterium avium subsp. paratuberculosis and $M$. avium strains: Comparison with IS900 and ISI 245 restriction fragment length polymorphism typing. J Clin Microbiol 2007, 45:2404-24I0.

23. Sevilla I, Garrido J, Geijo M, Juste R: Pulsed-field gel electrophoresis profile homogeneity of Mycobacterium avium subsp. paratuberculosis isolates from cattle and heterogeneity of those from sheep and goats. BMC Microbiology 2007, 7:12.

24. Motiwala AS, Li LL, Kapur V, Sreevatsan S: Current understanding of the genetic diversity of Mycobacterium avium subsp. paratuberculosis. Microb Infect 2006, 8:|406-1418.

25. Thibault VC, Grayon M, Boschiroli ML, Willery E, lix-Beguec C, Stevenson K, Biet F, Supply P: Combined Multilocus ShortSequence-Repeat and Mycobacterial Interspersed Repetitive Unit-Variable-Number Tandem-Repeat Typing of Mycobacterium avium subsp. paratuberculosis Isolates. J Clin Microbiol 2008, 46:409l-4094.

26. Djonne B, Pavlik I, Svastova P, Bartos M, Holstad G: IS900 restriction fragment length polymorphism (RFLP) analysis of Mycobacterium avium subsp. paratuberculosis isolates from goats and cattle in Norway. Acta Vet Scand 2005, 46:13-18.

27. Pavlik I, Bartl J, Dvorska L, Svastova P, du Maine R, Machackova M, Yayo Ayele W, Horvathova A: Epidemiology of paratuberculosis in wild ruminants studied by restriction fragment length polymorphism in the Czech Republic during the period 1995 1998. Vet Microbiol 2000, 77:231-25I.

28. Pavlik I, Horvathova A, Bartl J, Rychlik I: Study of epidemiology and pathogenesis of paratuberculosis using RFLP (Restriction Fragment Length Polymorphism). In Proceedings of the Fifth International Colloquium on Paratuberculosis: 29 September-4 October 1996: Madison, Wisconsin, USA Edited by: Chiodini RJ, Hines II ME, Collins MT. International Association for Paratuberculosis; 1997:202-2II.

29. Pavlik I, Bolske G, Englund S, Dvorska L, du Maine R, Svastova P, Viske $D$, Parmova I, Bazant J: Use of DNA fingerprinting for epidemiological studies of paratuberculosis in Sweden and the Czech Republic. In Proceedings of the Sixth International Colloquium on Paratuberculosis: 14-18 February 1999: Melbourne, Australia Edited by: Manning EJB, Collins MT. International Association for Paratuberculosis; 1999:176-187.

30. Pavlik I, Horvathova A, Dvorska L, Svastova P, du Maine R, Fixa B, Rychlik I: Homogeneity/heterogeneity of Mycobacterium avium subsp. paratuberculosis strains: Correlation between RFLP-type and source (animal, environment, human). In Proceedings of the Sixth International Colloquium on Paratuberculosis: 14-18 February 1999: Melbourne, Australia Edited by: Manning EJB, Collins M. International Association for Paratuberculosis; 1999:32 I-329.

3I. Mobius $\mathrm{P}$, Luyven $\mathrm{G}$, Hotzel $\mathrm{H}$, Kohler $\mathrm{H}$ : High genetic diversity among Mycobacterium avium subsp. paratuberculosis strains from German cattle herds shown by combination of IS900 restriction fragment length polymorphism analysis and mycobacterial interspersed repetitive unit-variable-number tandem-repeat typing. I Clin Microbiol 2008, 46:972-981.

32. Whipple $D$, Kapke $P$, Vary C: Identification of restriction fragment length polymorphisms in DNA from Mycobacterium paratuberculosis. I Clin Microbiol 1990, 28:256I-2564.

33. Moreira AR, Paolicchi F, Morsella C, Zumarraga M, Cataldi A, Fabiana $B$, Alicia A, Piet O, van Soolingen D, Isabel RM: Distribution of IS900 restriction fragment length polymorphism types among animal Mycobacterium avium subsp. paratuberculosis isolates from Argentina and Europe. Vet Microbiol 1999, 70:25I-259.

34. Caws M, Thwaites G, Dunstan S, Hawn TR, Lan NTN, Thuong NTT, Stepniewska K, Huyen MNT, Bang ND, Loc TH, Gagneux S, van Soolingen D, Kremer K, Sande M van der, Small P, Anh PTH, Chinh NT, Quy HT, Duyen NTH, Tho DQ, Hieu NT, Torok E, Hien TT, Dung NH, Nhu NTQ, Duy PM, Chau NV, Farrar J: The influence of host and bacterial genotype on the development of disseminated 
disease with Mycobacterium tuberculosis. Plos Pathogens 2008, 44:el000034.

35. Gollnick NS, Mitchell RM, Baumgart M, Janagama HK, Sreevatsand S, Schukken YH: Survival of Mycobacterium avium subsp. paratuberculosis in bovine monocyte-derived macrophages is not affected by host infection status but depends on the infecting bacterial genotype. Vet Immunol Immunopathol 2007, I 20:93-I05.

36. Janagama H, il Jeong K, Kapur V, Coussens P, Sreevatsan S: Cytokine responses of bovine macrophages to diverse clinical Mycobacterium avium subspecies paratuberculosis strains. BMC Microbiology 2006, 6: I0.

37. Motiwala AS, Janagama HK, Paustian ML, Zhu XC, Bannantine JP, Kapur V, Sreevatsan S: Comparative transcriptional analysis of human macrophages exposed to animal and human isolates of Mycobacterium avium subspecies paratuberculosis with diverse genotypes. Infect Immun 2006, 74:6046-6056.

38. O'Brien R, Mackintosh CG, Bakker D, Kopecna M, Pavlik I, Griffin JFT: Immunological and molecular characterization of susceptibility in relationship to bacterial strain differences in Mycobacterium avium subsp. paratuberculosis infection in the red deer (Cervus elaphus). Infect Immun 2006, 74:3530-3537.

39. Verna AE, Garcia-Pariente C, Munoz M, Moreno O, Garcia-Marin JF, Romano MI, Paolicchi F, Perez V: Variation in the immuno-pathological responses of lambs after experimental infection with different strains of Mycobacterium avium subsp. paratuberculosis. Zoonoses and Public Health 2007, 54:243-252.

40. Marsh IB, Whittington RJ: Genomic diversity in Mycobacterium avium: Single nucleotide polymorphisms between the $S$ and C strains of $M$. avium subsp. paratuberculosis and with $M$. $a$. avium. Mol Cell Probes 2007, 21:66-75.

4I. Reddacliff LA, Vadali A, Whittington RJ: The effect of decontamination protocols on the numbers of sheep strain Mycobacterium avium subsp. paratuberculosis isolated from tissues and faeces. Vet Microbiol 2003, 95:27I-282.

42. Whittington RJ, Marsh I, McAllister S, Turner MJ, Marshall DJ, Fraser CA: Evaluation of modified BACTEC I2B radiometric medium and solid media for culture of Mycobacterium avium subsp. paratuberculosis from sheep. J Clin Microbiol 1999, 37: 1077-1083.

43. Juste RA, Marco JC, Deocariz CS, Aduriz JJ: Comparison of different media for the isolation of small ruminant strains of Mycobacterium paratuberculosis. Vet Microbiol I99I, 28:385-390.

44. de Juan L, Alvarez J, Romero B, Bezos J, Castellanos E, Aranaz A, Mateos A, Dominguez $L$ : Comparison of four different culture media for isolation and growth of Type II and Type I/III Mycobacterium avium subsp. paratuberculosis strains isolated from cattle and goats. Appl Environ Microbiol 2006, 72:5927-5932.

45. Gumber S, Whittington RJ: Comparison of BACTEC 460 and MGIT 960 systems for the culture of Mycobacterium avium subsp. paratuberculosis $S$ strain and observations on the effect of inclusion of ampicillin in culture media to reduce contamination. Vet Microbiol 2007, I $19: 42-52$.

46. Beard PM, Rhind SM, Buxton D, Daniels MJ, Henderson D, Pirie A, Rudge K, Greig A, Hutchings MR, Stevenson K, Sharp JM: Natural paratuberculosis infection in rabbits in Scotland. J Comp Pathol 200I, I 24:290-299.

47. Judge J, Kyriazakis I, Greig A, Davidson RS, Hutchings MR: Routes of intraspecies transmission of Mycobacterium avium subsp. paratuberculosis in rabbits (Oryctolagus cuniculus): a field study. Appl Environ Microbiol 2006, 72:398-403.

48. Judge j, Davidson RS, Marion G, White PCL, Hutchings MR: Persistence of Mycobacterium avium subspecies paratuberculosis in rabbits: the interplay between horizontal and vertical transmission. J Appl Ecol 2007, 44:302-3II.

49. Singh SV, Singh PK, Singh AV, Sohal JS, Gupta VK, Vihan VS: Comparative efficacy of an indigenous 'inactivated vaccine' using highly pathogenic field strain of Mycobacterium avium subspecies paratuberculosis 'Bison type' with a commercial vaccine for the control of Capri-paratuberculosis in India. Vaccine 2007, 25:7102-71।10.

50. Pavlik I, Horvathova A, Dvorska L, Bartl J, Svastova P, du Maine R, Rychlik I: Standardisation of restriction fragment length polymorphism analysis for Mycobacterium avium subspecies paratuberculosis. J Microbiol Methods 1999, 38:155-167.

5I. MRI Mycobacteria Pulsed-Field Gel Electrophoresis Database [http://www.moredun.ac.uk/PFGE-mycobacteria]
52. Selander RK, Caugant DA, Ochman H, Musser JM, Gilmour MN Whittam TS: Methods of multilocus enzyme electrophoresis for bacterial population genetics and systematics. Appl Environ Microbiol 1 986, 5 I :873-884.

53. Mazars E, Lesjean S, Banuls AL, Gilbert M, Vincent V, Gicquel B, Tibayrenc $M$, Locht $C$, Supply $P$ : High-resolution minisatellite-based typing as a portable approach to global analysis of Mycobacterium tuberculosis molecular epidemiology. Proc Natl Acad Sci USA 200I, 98:1901-1906.

54. Hunter PR, Gaston MA: Numerical index of the discriminatory ability of typing systems: an application of Simpson's Index of Diversity. J Clin Microbiol 1988, 26:2465-2466.

55. Grundmann H, Hori S, Tanner G: Determining confidence intervals when measuring genetic diversity and the discriminatory abilities of typing methods for microorganisms. J Clin Microbiol 200I, 39:4190-4192.

56. Thibault VC, Grayon M, Boschiroli ML, Hubbans C, Overduin P, Stevenson K, Gutierrez MC, Supply P, Biet F: New variable-number tandem-repeat markers for typing Mycobacterium avium subsp. paratuberculosis and $M$. avium strains: Comparison with IS 900 and IS I 245 restriction fragment length polymorphism typing. J Clin Microbiol 2007, 45:2404-24I0.

Publish with Bio Med Central and every scientist can read your work free of charge

"BioMed Central will be the most significant development for disseminating the results of biomedical research in our lifetime. "

Sir Paul Nurse, Cancer Research UK

Your research papers will be:

- available free of charge to the entire biomedical community

- peer reviewed and published immediately upon acceptance

- cited in PubMed and archived on PubMed Central

- yours - you keep the copyright

Submit your manuscript here:

http://www.biomedcentral.com/info/publishing_adv.asp
BioMedcentral 